\title{
Phylogeny and Haplotype Analysis of Fungi Within the Fusarium incarnatum-equiseti Species Complex
}

\author{
H. Ramdial, R. K. Latchoo, F. N. Hosein, and S. N. Rampersad
}

The University of the West Indies, Department of Life Sciences, Faculty of Science and Technology, St. Augustine, Trinidad and Tobago, West Indies.

Accepted for publication 19 September 2016.

\begin{abstract}
Fusarium spp. are ranked among the top 10 most economically and scientifically important plant-pathogenic fungi in the world and are associated with plant diseases that include fruit decay of a number of crops. Fusarium isolates infecting bell pepper in Trinidad were identified based on sequence comparisons of the translation elongation factor gene (EF-1a) with sequences of Fusarium incarnatum-equiseti species complex (FIESC) verified in the FUSARIUM-ID database. Eighty-two isolates were identified as belonging to one of four phylogenetic species within the subclades FIESC-1, FIESC-15, FIESC-16, and FIESC-26, with the majority of isolates belonging to FIESC15. A comparison of the level of DNA polymorphism and phylogenetic inference for sequences of the internal transcribed spacer region (ITS1-5.8SITS2) and EF-1a sequences for Trinidad and FUSARIUM-ID type species was carried out. The ITS sequences were less informative, had lower haplotype diversity and restricted haplotype distribution, and resulted in poor resolution and taxa placement in the consensus maximum-likelihood tree. EF-1a sequences enabled strongly supported phylogenetic inference with highly resolved branching patterns of the 30 phylogenetic species

within the FIESC and placement of representative Trinidad isolates. Therefore, global phylogeny was inferred from EF-1a sequences representing 11 countries, and separation into distinct Incarnatum and Equiseti clades was again evident. In total, 42 haplotypes were identified: 12 were shared and the remaining were unique haplotypes. The most diverse haplotype was represented by sequences from China, Indonesia, Malaysia, and Trinidad and consisted exclusively of $F$. incarnatum isolates. Spain had the highest haplotype diversity, perhaps because both $F$. equiseti and $F$. incarnatum sequences were represented; followed by the United States, which contributed both $F$. equiseti and $F$. incarnatum sequences to the data set; then by countries representing Southeast Asia (China, Indonesia, Malaysia, Thailand, and Philippines) and Trinidad; both of these regions were represented by only $F$. incarnatum sequences. Trinidad shared two haplotypes with China and one haplotype with the United States for only F. incarnatum isolates. The findings of this study are important for devising disease management strategies and for understanding the phylogenetic relationships among members of the FIESC.
\end{abstract}

Trinidad $\left(10.6918^{\circ} \mathrm{N}, 61.2225^{\circ} \mathrm{W}\right)$ is the southern-most island in the West Indies and is located approximately seven miles off Venezuela's northeastern coast. The island is the larger of a twin island republic (Trinidad and Tobago) and is bordered by the Atlantic Ocean and Caribbean Sea. It was reported in 2011 that $540 \mathrm{~km}^{2}$ of the total land area $\left(5,131 \mathrm{~km}^{2}\right)$ is arable as defined by the Food and Agriculture Organization. In Trinidad, bell pepper crops are grown year-round in fields located in the northeast and south. Depending on the availability of seed, the most commonly grown varieties are 'Anaconda', 'Aristotle', 'Canape', and 'Paladin', with 'King Henry' being the most popular variety grown in 2012 (Mohammed 2013; Ramdial and Rampersad 2014). Growers generally use seedlings prepared by agricultural suppliers and seedling companies. Bell pepper fruit in Trinidad are sold and consumed as fresh fruit, without any undergoing any processing. Between 2006 and 2010, the acreage under production and the quantity harvested fluctuated (e.g., 505,000 kg in 2008 to $149,000 \mathrm{~kg}$ in 2009, with increased production to $369,000 \mathrm{~kg}$ in 2010) (Mohammed 2013). In addition to several marketing channels available throughout the country, Trinidad exports bell pepper to Barbados, with an annual quota to be maintained due to an agricultural trade agreement for export of certified produce between the two countries. There has also been a steady increase in the importation of bell pepper from the United States between 2006 and

Corresponding author: S. N. Rampersad; E-mail address: sephra.rampersad@sta.uwi.edu

*The $\boldsymbol{e}$-Xtra logo stands for "electronic extra" and indicates that two supplementary tables are published online.

(C) 2017 The American Phytopathological Society
2010 (Mohammed 2013). The relatively high production cost faced by local growers, poor performance of the available varieties against diseases affecting pepper in Trinidad, yield loss (estimated to be between 20 to $40 \%$ in fields that were sampled) incurred due to disease, and changes in market value of locally produced pepper compared with imported pepper have resulted in abandoned fields, usually at midharvesting stage.

Symptoms of Fusarium infection in bell pepper are seen as a single, watery lesion with evidence of internal fruit rot, both of which reduce the marketability of the fruit. The lesion may begin at the calyx and extend downward but it can develop anywhere on the fruit. To date, the disease had not been reported prior to 2010, when the last survey of the main production areas in Trinidad was carried out (Ramdial and Rampersad 2014). Management of the disease is based on chemical control; however, there is no registered fungicide for the control of Fusarium fruit rot of bell pepper in Trinidad. There are also no resistant cultivars available and cultural methods such as field sanitation and rotation away from solanaceous crops for a minimum of 2 years have proven ineffective at controlling the disease. The relatively recent emergence of Fusarium fruit rot of bell pepper fruit in Trinidad may be explained by a combination of epidemic-associated fungus, host, and environmental factors; for example, (i) increased susceptibility of bell pepper cultivars to Fusarium disease; (ii) low efficacy of chemical control; (iii) production of small, dry asexual spores by the fungus which survive in dry weather conditions and which may cause infection via wind dispersal; and (iv) wetter conditions of the rainy season may result in higher moisture levels on flowers that encourage fungal growth and infection of the stigma or rain splash from the soil onto lowlying fruit. 
Fusarium spp. also produce a diverse range of mycotoxins, including trichothecenes (Woloshuk and Shim 2013), that contaminate agricultural products and render them unsuitable for human or animal consumption. There is also evidence to suggest that trichothecenes can promote or suppress virulence which may be host-specific or specific to the individual Fusarium spp. (Bai et al. 2002; Desmond et al. 2008; Ilgen et al. 2008; Desjardins et al. 1996; Proctor et al. 1995). Fusarium mycotoxins can be associated with both acute and chronic toxic effects, the extent of which may rely on the mycotoxin type, the level and duration of exposure, the species that is exposed, and the relative age of the affected organism (Antonissen et al. 2014). This underlines the importance of accurate identification of the pathogen and knowledge of phylogenetic relationships with mycotoxin producers.

Fusarium spp. are ranked among the most economically and scientifically important plant-pathogenic fungi in the world (Dean et al. 2012). The genus consists of filamentous ascomycete fungi (Sordariomycetes: Hypocreales: Nectriaceae) that are associated with several diseases, including wilts, blights, and necrosis of various horticultural, field, ornamental, and forest species in both agricultural and naturally occurring ecosystems (Ma et al. 2013). Fusarium lactis was recently reported as a common pathogen of pepper, in addition to several other minor pathogens (e.g., F. proliferatum, F. subglutinans, and $F$. oxysporum) (Van Poucke et al. 2012).

The Fusarium genus includes close to 300 phylogenetic species; however, with respect to describing new species, many researchers have agreed on the need for a revision of classification because studies have shown that intra- and interspecific boundaries as currently defined within the genus may be inaccurate or poorly resolved (Aoki et al. 2014; Benyon et al. 2000; Moretti 2009; O'Donnell et al. 2004; Skovgaard et al. 2003; Taylor et al. 2000; Torp and Nirenberg 2004; Waalwijk et al. 1996). Phylogenetic analysis has primarily focused on inferring hypothetical evolutionary relationships of agriculturally or medically important isolates (O'Donnell et al. 2010). For DNA-based identification of fungi in general, the universal barcoding region is the internal transcribed sequence (ITS) of ribosomal DNA (rDNA), and it is also the most commonly sequenced DNA region for investigating the molecular ecology of a range of fungi (Peay et al. 2008; Stielow et al. 2015). For Fusarium spp., this region is too conserved and does not distinguish among members within a given species complex (O' Donnell et al. 2015). However, several recent publications still describe genetic diversity of various Fusarium spp. based on ITS sequences (Arif et al. 2014; Dubey et al. 2014; Soren et al. 2015; Zarrin et al. 2016). Protein-coding genes-for example, $\beta$-tubulin

TABLE 1. Fusarium incarnatum-equiseti species complex (FIESC) designation and haplotype distribution for FIESC and Trinidad isolates

\begin{tabular}{|c|c|c|c|c|}
\hline Isolate $^{\mathrm{a}}$ & Field location ${ }^{b}$ & $\begin{array}{l}\text { EF-1a FIESC } \\
\text { designation }^{c}\end{array}$ & $\begin{array}{l}\text { EF-1a haplotype among } \\
\text { FIESC and Trinidad isolates }\end{array}$ & $\begin{array}{l}\text { ITS haplotype among } \\
\text { FIESC and Trinidad isolates }\end{array}$ \\
\hline *TT-1 & Aranguez & FIESC $15 \mathrm{c}$ & EF-Hap_27 & ITS-Hap1 \\
\hline *TT-2 & Macoya & FIESC $15 c$ & EF-Hap_27 & ITS-Hap1 \\
\hline TT-3 & Aranguez & FIESC $15 \mathrm{a}$ & EF-Hap_27 & ITS-Hap1 \\
\hline TT-4 & Aranguez & FIESC $15 \mathrm{a}$ & EF-Hap_27 & ITS-Hap2 \\
\hline TT-5 & Aranguez & FIESC $15 \mathrm{a}$ & EF-Hap_27 & ITS-Hap1 \\
\hline TT-6 & Aranguez & FIESC $15 \mathrm{a}$ & EF-Hap_27 & ITS-Hap1 \\
\hline *TT-7 & Macoya & FIESC15a & EF-Hap_27 & ITS-Hap1 \\
\hline TT-8 & Aranguez & FIESC 1a & EF-Hap_48 & ITS-Hap12 \\
\hline TT-9 & Maloney & FIESC15a & EF-Hap_31 & ITS-Hap1 \\
\hline TT-10 & Aranguez & FIESC $16 \mathrm{c}$ & EF-Hap_28 & ITS-Hap3 \\
\hline TT-11 & Aranguez & FIESC $15 \mathrm{a}$ & EF-Hap_27 & ITS-Hap2 \\
\hline TT-12 & Aranguez & FIESC $15 \mathrm{a}$ & EF-Hap_27 & ITS-Hap2 \\
\hline TT-13 & Aranguez & FIESC $15 \mathrm{a}$ & EF-Hap_27 & ITS-Hap2 \\
\hline TT-14 & Aranguez & FIESC $16 \mathrm{c}$ & EF-Hap_28 & ITS-Hap3 \\
\hline TT-15 & Aranguez & FIESC $16 \mathrm{c}$ & EF-Hap_28 & ITS-Hap3 \\
\hline *TT-16 & Aranguez & FIESC 16c & EF-Hap_28 & ITS-Hap2 \\
\hline TT-17 & Aranguez & FIESC 16c & EF-Hap_28 & ITS-Hap2 \\
\hline *TT-18 & Maloney & FIESC 16c & EF-Hap_28 & ITS-Hap2 \\
\hline TT-19 & Aranguez & FIESC $15 \mathrm{a}$ & EF-Hap_27 & ITS-Hap1 \\
\hline TT-20 & Aranguez & FIESC $15 \mathrm{a}$ & EF-Hap_27 & ITS-Hap1 \\
\hline *TT-21 & Macoya & FIESC $16 \mathrm{c}$ & EF-Hap_28 & ITS-Hap2 \\
\hline TT-22 & Aranguez & FIESC $15 \mathrm{a}$ & EF-Hap_27 & ITS-Hap1 \\
\hline TT-23 & Aranguez & FIESC $15 \mathrm{a}$ & EF-Hap_27 & ITS-Hap1 \\
\hline TT-24 & Aranguez & FIESC $15 a$ & EF-Hap_27 & ITS-Hap2 \\
\hline TT-25 & Aranguez & FIESC $15 \mathrm{a}$ & EF-Hap_27 & ITS-Hap1 \\
\hline TT-26 & Aranguez & FIESC $15 \mathrm{a}$ & EF-Hap_27 & ITS-Hap1 \\
\hline TT-27 & Aranguez & FIESC15a & EF-Hap_27 & ITS-Hap1 \\
\hline TT-28 & Aranguez & FIESC15a & EF-Hap_27 & ITS-Hap1 \\
\hline TT-29 & Aranguez & FIESC15a & EF-Hap_27 & ITS-Hap1 \\
\hline TT-30 & Aranguez & FIESC $16 \mathrm{c}$ & EF-Hap_28 & ITS-Hap1 \\
\hline TT-31 & Aranguez & FIESC15a & EF-Hap_27 & ITS-Hap1 \\
\hline *TT-32 & Aranguez & FIESC 26b & EF-Hap_47 & ITS-Hap2 \\
\hline TT-33 & Aranguez & FIESC15a & EF-Hap_27 & ITS-Hap1 \\
\hline TT-34 & Aranguez & FIESC $15 \mathrm{a}$ & EF-Hap_27 & ITS-Hap1 \\
\hline TT-35 & Aranguez & FIESC $15 \mathrm{a}$ & EF-Hap_27 & ITS-Hap2 \\
\hline TT-36 & Aranguez & FIESC $15 \mathrm{a}$ & EF-Hap_27 & ITS-Hap1 \\
\hline TT-37 & Aranguez & FIESC $15 a$ & EF-Hap_27 & ITS-Hap1 \\
\hline TT-38 & Aranguez & FIESC15a & EF-Hap_27 & ITS-Hap1 \\
\hline
\end{tabular}

a Isolates with an asterisk (*) were selected as the representative isolates for inclusion in the phylogenetic analyses.

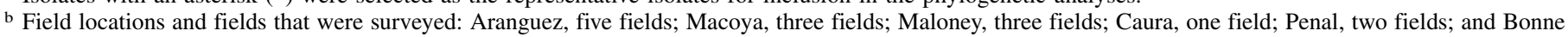
Aventure, two fields. FIESC isolates were not detected in fields located in Caura and Penal.

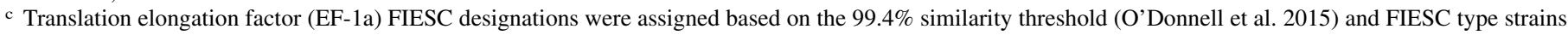
were mined from FUSARIUM-ID database.

d Underscore (_) was used in the EF-1a haplotype designations to distinguish them from the ITS haplotypes. 
(TUB), translation elongation factor 1-a (EF-1a), and RNA polymerase II subunits 1 and 2 (RPB1 and RPB2) - have been recommended because these regions are easily sequenced and sequences can be aligned across the entire genus (O'Donnell et al. 2000, 2010, 2015). The EF-1a gene sequence, with a sequence similarity threshold of $99.4 \%$, is a suitable genetic marker for discriminating among Fusarium spp., and allows discrimination of genotypes at the subspecific level (Geiser et al. 2004; O'Donnell et al. 2015). Sequence data from only one of these loci (RPB1 and RPB2 or EF1a) is required for reliable identification of unknown isolates and for phylogenetic analysis, provided that the similarity threshold is obtained (O'Donnell et al. 2015).

Genetic diversity and phylogenetic analyses inferred from multiple sequence comparisons of local and global isolates can reveal evolutionary relationships which may or may not coincide with geographical region or host species. A high degree of genetic diversity can also indicate greater ability to adapt to changing environmental conditions and may reflect increased biological fitness of these genotypes. The tropics are among the world's oldest, most diverse ecosystems and Fusarium spp., in such habitats, have been represented by pathogens that are coevolving with their plant host, as well as by newly introduced pathogens (Ploetz 2006). It is hypothesized that, although there will be shared genotypes between Trinidad and other tropical regions, there may also be a genetic signature that is unique to the Trinidad isolates. The objectives of this study, therefore, were to (i) confirm the identity of Fusarium spp. infecting bell pepper in Trinidad; (ii) compare the level of DNA polymorphism of ITS and EF-1a sequences of type species and Trinidad isolates; (iii) infer the phylogenetic relationships of F. incarnatum-equiseti species complex (FIESC) type species, isolates from Trinidad, and isolates from other countries; and (iv) determine the haplotype diversity and distribution among FIESC isolates. Preliminary findings which identified the pathogen as F. incarnatum were published by Ramdial et al. (2016).

\section{MATERIALS AND METHODS}

Fungal isolate collection. Sixteen bell pepper fields were sampled at the harvesting stage in fields located in the main areas of year-round production. Symptomatic fruit were collected and surface disinfected by rinsing in $70 \%$ ethanol for $1 \mathrm{~min}$, followed by another rinse in $0.6 \%$ sodium hypochlorite solution for $1 \mathrm{~min}$. Samples were then washed three times in sterilized distilled water and dried on sterile tissue paper in a laminar flow hood placed at the center of ethanol-amended agar plates (2\% water agar amended with $5 \%$ absolute ethanol, streptomycin at $50 \mathrm{mg} / \mathrm{liter}$, and tetracycline at $50 \mathrm{mg} /$ liter) (Sigma-Aldrich Co.). Plates were incubated for 5 days at $25^{\circ} \mathrm{C}$ in the dark. After incubation, a $4-\mathrm{mm}^{3}$

TABLE 1. (continued from preceding page)

\begin{tabular}{|c|c|c|c|c|}
\hline Isolate $^{\mathrm{a}}$ & Field location ${ }^{b}$ & $\begin{array}{l}\text { EF-1a FIESC } \\
\text { designation }^{c}\end{array}$ & $\begin{array}{l}\text { EF-1a haplotype among } \\
\text { FIESC and Trinidad isolates }\end{array}$ & $\begin{array}{l}\text { ITS haplotype among } \\
\text { FIESC and Trinidad isolates }\end{array}$ \\
\hline TT-39 & Aranguez & FIESC15a & EF-Hap_27 & ITS-Hap1 \\
\hline TT-40 & Aranguez & FIESC 1a & EF-Hap_48 & ITS-Hap12 \\
\hline *TT-41 & Мacoya & FIESC $26 b$ & EF-Hap_47 & ITS-Hap2 \\
\hline *TT-42 & Maloney & FIESC $26 b$ & EF-Hap_47 & ITS-Hap2 \\
\hline TT-43 & Aranguez & FIESC $15 a$ & EF-Hap_27 & ITS-Hap1 \\
\hline TT-44 & Aranguez & FIESC $15 a$ & EF-Hap_27 & ITS-Hap2 \\
\hline TT-45 & Macoya & FIESC $15 \mathrm{a}$ & EF-Hap_27 & ITS-Hap1 \\
\hline TT-46 & Macoya & FIESC $15 \mathrm{a}$ & EF-Hap_27 & ITS-Hap1 \\
\hline TT-47 & Macoya & FIESC15a & EF-Hap_27 & ITS-Hap1 \\
\hline TT-48 & Macoya & FIESC $15 \mathrm{a}$ & EF-Hap_27 & ITS-Hap1 \\
\hline TT-49 & Maloney & FIESC $15 \mathrm{a}$ & EF-Hap_27 & ITS-Hap1 \\
\hline TT-50 & Maloney & FIESC $16 \mathrm{c}$ & EF-Hap_28 & ITS-Hap1 \\
\hline TT-51 & Maloney & FIESC $15 a$ & EF-Hap_27 & ITS-Hap1 \\
\hline TT-52 & Maloney & FIESC $16 \mathrm{c}$ & EF-Hap_28 & ITS-Hap1 \\
\hline TT-53 & Maloney & FIESC $16 c$ & EF-Hap_28 & ITS-Hap1 \\
\hline TT-54 & Aranguez & FIESC $16 \mathrm{c}$ & EF-Hap_28 & ITS-Hap1 \\
\hline TT-55 & Aranguez & FIESC $16 \mathrm{c}$ & EF-Hap_28 & ITS-Hap1 \\
\hline TT-56 & Aranguez & FIESC $15 \mathrm{a}$ & EF-Hap_27 & ITS-Hap1 \\
\hline TT-57 & Aranguez & FIESC $15 a$ & EF-Hap_27 & ITS-Hap1 \\
\hline TT-58 & Aranguez & FIESC 15a & EF-Hap_27 & ITS-Hap1 \\
\hline TT-59 & Aranguez & FIESC $16 \mathrm{c}$ & EF-Hap_28 & ITS-Hap1 \\
\hline TT-60 & Aranguez & FIESC $16 \mathrm{c}$ & EF-Hap_28 & ITS-Hap1 \\
\hline TT-61 & Aranguez & FIESC $16 \mathrm{c}$ & EF-Hap_28 & ITS-Hap1 \\
\hline TT-62 & Aranguez & FIESC $16 c$ & EF-Hap_28 & ITS-Hap1 \\
\hline TT-63 & Aranguez & FIESC $15 a$ & EF-Hap_27 & ITS-Hap1 \\
\hline TT-64 & Bonne aventure & FIESC $15 \mathrm{a}$ & EF-Hap_27 & ITS-Hap1 \\
\hline TT-65 & Bonne aventure & FIESC $15 \mathrm{a}$ & EF-Hap_27 & ITS-Hap2 \\
\hline TT-66 & Bonne aventure & FIESC $15 \mathrm{a}$ & EF-Hap_27 & ITS-Hap1 \\
\hline TT-67 & Bonne aventure & FIESC $15 a$ & EF-Hap_27 & ITS-Hap1 \\
\hline TT-68 & Bonne aventure & FIESC15a & EF-Hap_27 & ITS-Hap1 \\
\hline TT-69 & Bonne aventure & FIESC $15 \mathrm{a}$ & EF-Hap_27 & ITS-Hap1 \\
\hline TT-70 & Aranguez & FIESC $15 \mathrm{a}$ & EF-Hap_27 & ITS-Hap1 \\
\hline TT-71 & Aranguez & FIESC $16 c$ & EF-Hap_28 & ITS-Hap2 \\
\hline TT-72 & Aranguez & FIESC 16c & EF-Hap_28 & ITS-Hap2 \\
\hline TT-73 & Aranguez & FIESC 16c & EF-Hap_28 & ITS-Hap2 \\
\hline TT-74 & Aranguez & FIESC $16 \mathrm{c}$ & EF-Hap_28 & ITS-Hap2 \\
\hline TT-75 & Aranguez & FIESC $15 a$ & EF-Hap_27 & ITS-Hap2 \\
\hline TT-76 & Aranguez & FIESC $15 \mathrm{a}$ & EF-Hap_27 & ITS-Hap2 \\
\hline TT-77 & Aranguez & FIESC 16c & EF-Hap_28 & ITS-Hap2 \\
\hline TT-78 & Aranguez & FIESC $15 a$ & EF-Hap_27 & ITS-Hap2 \\
\hline TT-79 & Aranguez & FIESC $15 a$ & EF-Hap_27 & ITS-Hap2 \\
\hline TT-80 & Aranguez & FIESC $15 a$ & EF-Hap_27 & ITS-Hap2 \\
\hline TT-81 & Aranguez & FIESC $16 \mathrm{c}$ & EF-Hap_28 & ITS-Hap2 \\
\hline TT-82 & Bonne aventure & FIESC $15 a$ & EF-Hap_27 & ITS-Hap1 \\
\hline
\end{tabular}


block of agar taken from the advancing mycelial edge of a 5-day-old culture was removed and placed in the center of a potato dextrose agar (PDA) plate (Oxoid Ltd.) supplemented with streptomycin at $50 \mathrm{mg} / \mathrm{liter}$ and tetracycline at $50 \mathrm{mg} /$ liter. Cultures were incubated for 7 days at $25^{\circ} \mathrm{C}$ in the dark. Pure cultures were obtained by standard serial dilution and from hyphal tips and maintained on PDA slants at $4^{\circ} \mathrm{C}$ for temporary storage, and as conidial suspensions in $50 \%$ glycerol at $-70^{\circ} \mathrm{C}$ for long-term storage.

Morphological characterization. Single-spore subcultures were grown on PDA and carnation leaf agar (CLA) (Leslie and Summerell 2006). Plates were incubated at $25^{\circ} \mathrm{C}$ for 7 days in alternating dark and light 12 -h photoperiods. Colony and conidia characteristics were recorded and included colony growth rate after 5 days of growth on CLA, colony texture and pigmentation in aerial and reverse views, appearance and mean size of 20 welldeveloped macro- and microconidia, and number of septa. Four replicates for each isolate were used and the experiment was conducted twice.

Pathogenicity tests. A $10^{5}$ conidia $\mathrm{ml}^{-1}$ suspension $(20 \mu \mathrm{l}$ of each isolate) was used to inoculate three nonwounded and three wounded sites of five healthy, mature Aristotle pepper fruit. Negative control fruit were treated with sterile distilled water. Inoculated fruit were kept in a moist chamber at $26^{\circ} \mathrm{C}( \pm 2)$ for 5 days. Fruit were examined for the development of symptoms over this 5-day incubation period. Pathogenicity tests were conducted twice. The identity of the fungus associated with symptomatic fruit was determined based on EF-1a sequence comparisons as described in the section below.

DNA extraction, polymerase chain reaction amplification, and sequencing. Fresh mycelium was harvested from cultures grown in potato dextrose broth supplemented with streptomycin at $50 \mathrm{mg} /$ liter and tetracycline at $50 \mathrm{mg} /$ liter for 4 days at $28^{\circ} \mathrm{C}$ at $120 \mathrm{rpm}$ in a rotary shaker. Fungal genomic DNA was prepared using the hexadecyltrimethylammonium bromide extraction method and a working DNA concentration of $10 \mathrm{ng} / \mu \mathrm{l}$ was used in polymerase chain reaction (PCR) amplification. The ITS region of rDNA (White et al. 1990) and the EF-1a gene were amplified using published cycling parameters (O'Donnell et al. 2004, 2015). PCR products were sequenced directly and in both directions (Amplicon Express). Nucleotide sequences were aligned using the MAFFT alignment program (http://mafft.cbrc.jp/alignment/server/). Sequences were then edited using Bioedit sequence alignment editor software, version 7.2.5 (http://www.mbio.ncsu.edu/bioedit/page2. html).

DNA polymorphism. There is evidence to suggest that the reason for the observed discordance in the classification schemes for Fusarium may be due to misidentification of isolates (Thrane 2001). Only verified sequences of isolates of FIESC retained in the FUSARIUM-ID database were mined and served as type strains within the FIESC for this study (O'Donnell et al. 2004, 2015). These sequences formed type strain sequence data set where $N_{\mathrm{EF}-1 \mathrm{a}}=74$ and $N_{\text {ITS }}=92$ (Supplementary Table S1). The global sequence data set contained only published or verified sequences deposited in GenBank (Supplementary Table S2) together with representative Trinidad sequences where $N_{\mathrm{EF}-1 \mathrm{a}}=90$.

The relative degree of DNA polymorphism was determined for both the ITS and EF-1a gene sequences using DNA Sequence Polymorphism software (DNASP), version 5.10 (Librado and Rozas 2009; Rozas et al. 2003) and ARLEQUIN, version 3.1 (Excoffier et al. 2005) and was based on the following parameters: number of polymorphic sites (S), number of mutations (Eta), number of haplotypes $(h)$, haplotype diversity $(\mathrm{H} d)$, Watterson's estimator $\theta(S)$ and $(\pi)$, nucleotide diversity $(\pi)$, and the number of nucleotide differences $(k)$. This data would also be used as an indicator of phylogenetic informativeness for each gene sequence data set.

Data sets. Three data sets were generated: (i) FUSARIUM-ID FIESC ITS sequences for all 30 type strains, (ii) FUSARIUM-ID
FIESC EF-1a sequences for the 30 type strains, and (iii) FIESC sequences mined from GenBank as a sampling of isolates from 10 different countries. There were no a priori assumptions made in mining the sequences, except that the sequences conformed to the recommendations of Geiser et al. (2004) and O'Donnell et al. (2015) and were correctly identified as F. equiseti, F. incarnatum, or $F$. incarnatum/equiseti. Three representative sequences of Trinidad isolates (representing the FIESC 15, FIESC 16, FIESC 26, and FIESC 1 subclades) were included in the phylogenetic analyses. All GenBank accession numbers and FUSARIUM-ID identifiers are reported.

Phylogenetic inference. Maximum-likelihood (ML) analyses were conducted for separate ITS and EF-1a sequence data sets. Phylogenetic inference based on the EF-1a datasets was carried out, using ML implemented in Genetic Algorithm for Rapid Likelihood Inference (GARLI) 2.1 (Cummings et al. 2008; Zwickl 2006) and in MEGA7 (Tamura et al. 2013). Selection of the best models of nucleotide substitution for the ML analyses was carried out and, based on the highest ML score, all sequence data sets were subjected to the GTR $+\mathrm{I}+\mathrm{G}$ model. The rooted ML tree is shown and was generated from bootstrapping 1,000 replicates. The trees were rooted with $F$. concolor (Castellá and Cabañes 2014).

Haplotype analysis. Sequences of the global EF-1a sequence data set were aligned using MAFFT software. The alignment was imported into Bioedit v. 7.0.9. Sequences were again visually inspected, manually adjusted, and realigned in preparation for importing into molecular statistical programs. Detection of recombination was carried out using the Recombination Analysis Tool (Etherington et al. 2005) because recombination in the sequences would confound genealogical relationships and has the potential to result in overlapping haplotypes (Carbone and Kohn 2004).

A haplotype network to visualize the relationships among haplotypes for the global EF-1a sequence data set was calculated using PopART v. 1.7 (http://popart.otago.ac.nz) (Leigh and Bryant 2015). A TCS network, which is a parsimony-based method of analysis, was constructed for the aligned haplotype sequences (Clement et al. 2002; Templeton et al. 1992). Default settings of a 1:1 transition/transversion ratio and an $\varepsilon$ value set at 0 were initially used. The ratio was determined using MEGA6 (Tamura et al. 2013) and the estimated transition/transversion bias (R) was found to be 1.49 . The default setting was then changed in PopART and the networks were redrawn. This had no meaningful effect on the networks generated. Similarly, the values of $\varepsilon$ were changed from 0 to 10 , which resulted in longer calculation time. Exceeding this $\varepsilon$ value resulted in an increase in the pattern complexity of interconnecting nodes of the different groupings, with greater difficulty in interpreting the networks.

\section{RESULTS}

Morphology and growth rate. In total, 82 isolates identified as belonging to the FIESC were characterized in this study based on morphological traits, pathogenicity tests, and sequencing of the EF-1a and ITS gene regions. For purified isolates grown on CLA, colonies were dense, with floccular aerial mycelium, and cream to salmon coloration in reverse. Microconidia were single celled, hyaline, nonseptate, and ovoid, and measured 10 to 12 by 3 to $4 \mu \mathrm{m}$. Macroconidia were four to five septate, slightly curved and tapered at apex, and measured 28 to 31 by 3 to $5 \mu \mathrm{m}$. Isolates were considered to be fast growing, with a mean growth rate on of $4.5 \pm$ $0.2 \mathrm{~mm} /$ day.

Pathogenicity tests. Koch's postulates were fulfilled because the fungus was recovered from inoculated wounded fruit showing symptoms of disease similar to those observed in the field. A single watery lesion developed at wounded inoculation sites on each of the five fruits for each isolate. No lesions developed in the healthy 
control fruit treated with sterile distilled water. EF-1a sequences of the recovered isolates were identified as F. incarnatum (Desm.) Sacc. 1886, which belongs to the FIESC.

DNA polymorphism. Comparisons of chromatograms and sequences of the Trinidad isolates were carried out against DNA sequences, alignments, and corrected ABI sequence chromatograms in the FUSARIUM-ID database (http://isolate.fusariumdb. org/blast.php) in addition to sequences in GenBank (http://www. ncbi.nlm.nih.gov/) according to the recommendations of Geiser et al. (2004), O'Donnell et al. (2010, 2015), and web guides for using FUSARIUM-ID (http://isolate.fusariumdb.org/guide.php).

The percent sequence similarity for Trinidad isolates $(N=82)$ was determined after comparison with sequences of the FUSARIUM-ID database, and the values ranged from 99.3 to $100 \%$ sequence similarity, well within the threshold reported by O'Donnell et al. (2015). The pathogen was identified as F. incarnatum (Desm.) Sacc. 1886, which belongs to the FIESC. The majority of the isolates were $F$. incarnatum species type and were identified as FIESC-15 (representative sequence submitted to GenBank, KR003731), with fewer isolates belonging to type strains FIESC-16 and FIESC-26 (Table 1).

The ITS sequences had a much lower number of polymorphic sites than the EF-1a sequences (Tables 2 and 3). Concomitantly, this gene region also had a lower number of mutations. Nucleotide diversity was lower for the ITS sequences than for the EF-1a sequences. This implies that the mean number of nucleotide substitutions per site between any two randomly selected DNA sequences of the EF-1a sequences was greater than that of the ITS sequences.

Phylogenetic inference. Phylogeny was poorly resolved in the ML ITS tree generated using type strain sequences. Bootstrap score (bs) support was weak (bs $>50 \%$ ) and there was very low confidence in placement of sequences with mostly polytomic branching patterns. The ITS sequences were not variable enough to allow for resolution of the isolates into discrete subclades and did not identify Trinidad isolates to the subclade level (ML tree not shown).

Branches were well supported for the EF-1a ML phylogenetic tree constructed for type strain sequences and were largely separated according to type strain and phylogenetic species (Fig. 1A and B). The analysis involved 145 nucleotide sequences. Trinidad isolates were positioned within the $F$. incarnatum grouping (FIESC-15, -16, and -26) and only one Trinidad isolate was found to be most similar to other $F$. equiseti sequences (FIESC-1). Therefore, there were four phylogenetic species identified in the Trinidad data set. The branches were supported by high bootstrap scores (bs > 75\%). There was also clear separation of $F$. equiseti and $F$. incarnatum species into two distinct clusters (bs $>50 \%$ ). The ML tree generated by GARLI had similar topology (tree not shown).

The phylogenetic relationships among global isolates of the FIESC complex were inferred by ML analysis of EF-1a sequences because the ITS sequences in the data set were too invariable for accurate resolution of phylogeny. There was no evidence of recombination within the EF-1a sequences. There was an apparent

TABLE 2. DNA polymorphism data for Fusarium incarnatum-equiseti species complex (FIESC) FUSARIUM-ID type strains and Trinidad isolates based on internal transcribed spacer (ITS) and translation elongation factor (EF-1a) gene sequence comparisons

\begin{tabular}{lcc}
\hline DNA polymorphism parameter & EF-1a & ITS \\
\hline Number of sequences & 74 & 92 \\
Selected region analyzed & $1-445$ & $1-508$ \\
Number of polymorphic sites, $S$ & 130 & 22 \\
Number of mutations, Eta & 171 & 23 \\
Number of haplotypes, $h$ & 48 & 11 \\
Haplotype diversity, H $d$ & 0.977 & 0.814 \\
Nucleotide diversity, $\pi$ & 0.051 & 0.004 \\
$\theta(S)$ & 0.081 & 0.009 \\
$\theta(\pi)$ & 0.055 & 0.004 \\
Number of nucleotide differences, $k$ & 20.535 & 1.493 \\
\hline
\end{tabular}

separation of isolates identified as $F$. equiseti and those as $F$. incarnatum based on the metadata profile of the sequences mined from GenBank. Trinidad isolates clustered with the other F. incarnatum sequences in the data set. The ML tree reconstructed using GARLI had a similar topology when branching patterns and branch support were compared (tree not shown). There was evidence of clustering based on type strain because $F$. equiset $i$ isolates from Spain formed a separate, moderately supported cluster ( $\mathrm{bs}=68 \%$ ) which represented the FIESC-5 type strain. Isolates from Northern Europe (i.e., Denmark and Norway) and the United States were also grouped into a separate cluster with moderate support (bs $=99 \%$ ), and this represented the FIESC-25 type strain.

Within the F. incarnatum cluster, isolates from Spain, Philippines, and China formed a highly supported and distinct group (bs = 99\%) along with three Trinidad isolates, and this cluster represented the FIESC-26 species. Another moderately supported branch was shared among the remaining five Trinidad isolates and isolates from China, the United States, Indonesia, and Malaysia, which represented the FIESC-15 and -16 phylogenetic species.

Haplotype distribution: FIESC sequence data set. For the FIESC type strains data set, the ITS sequences exhibited a haplotype diversity of 0.814 whereas the EF-1a sequences exhibited a haplotype diversity of 0.977 and the haplotypes from the EF-1a sequences were more diverse than those identified for the ITS sequences. As such, haplotype diversity was higher for the EF-1a sequences than the ITS sequences. With respect to the ITS sequences, there were 12 haplotypes in the entire 92-sequence data set, 3 of which had Trinidad isolate membership (Table 1). Haplotype 1 exhibited the highest frequency within the ITS sequences, being generated from 22 sequences (both Trinidad sequences and Fusarium type strain sequences). On the other hand, Haplotypes $4-5,-9,-11$, and -12 exhibited the lowest frequencies among the ITS sequences, and were generated from only one sequence each. In comparison, for the type strain data set, 48 haplotypes were obtained for the EF-1a sequences, each generated from either the Fusarium type strain sequences or the Trinidad sequences. Haplotype 27 exhibited the highest frequency among the EF-1a sequences (Table 1). Haplotypes 1-2, 4, 6-7, 8, 10-16, 19, 21-23, $25,29,31-34,36-45$, and 48 exhibited the lowest frequencies among the EF-1a sequences, being generated from only one sequence each.

Haplotype distribution: Global sequence data set. For the global EF-1a sequence data set, there were 42 haplotypes detected based on sequence analysis of 79 isolates, which represented 11 different countries (Table 4). An analysis of haplotypes revealed that $50 \%$ of the total number of haplotypes detected were generated from insertion/deletion type mutations (InDels) using a multiallelic model in DNASP (Table 5). There were 46 singleton variable sites detected and these largely accounted for the remaining haplotypes obtained. Haplotype and nucleotide diversities are generally considered to be low where $\mathrm{H} d$ and $\pi$ are less than 0.5. Analysis of the global EF-1a sequences revealed that both indices were high

TABLE 3. DNA polymorphism data for global isolates of the Fusarium incarnatum-equiseti species complex (FIESC) based on translation elongation factor (EF-1a) gene sequence comparisons

\begin{tabular}{lc}
\hline DNA polymorphism parameter & EF-1a \\
\hline Number of sequences & 79 \\
Selected region analyzed & $1-395$ \\
Number of polymorphic sites, S & 151 \\
Number of mutations, Eta & 180 \\
Number of haplotypes, $h$ & 42 \\
Haplotype diversity, H $d$ & 0.958 \\
Nucleotide diversity, $\pi$ & 0.073 \\
$\theta(S)$ & 0.116 \\
$\theta(\pi)$ & 0.081 \\
Number of nucleotide differences, $k$ & 25.325 \\
\hline
\end{tabular}


( $\mathrm{H} d=0.958$ and $\pi=0.073)$. Tests of the standard neutral model for a demographically stable population-Tajima's D (Tajima 1989), Fu and Li's F*, and Fu and Li's D* (Fu 1997; Fu and Li 1993)—were carried out on the EF-1a sequences and it was found that statistics of neutrality were negative and not significant at $P \geq 0.10$, perhaps due to the intronic regions present in the EF-1a sequence.

A consensus maximum-parsimony (MP) tree was inferred for the haplotype sequences generated and the topological tree is presented

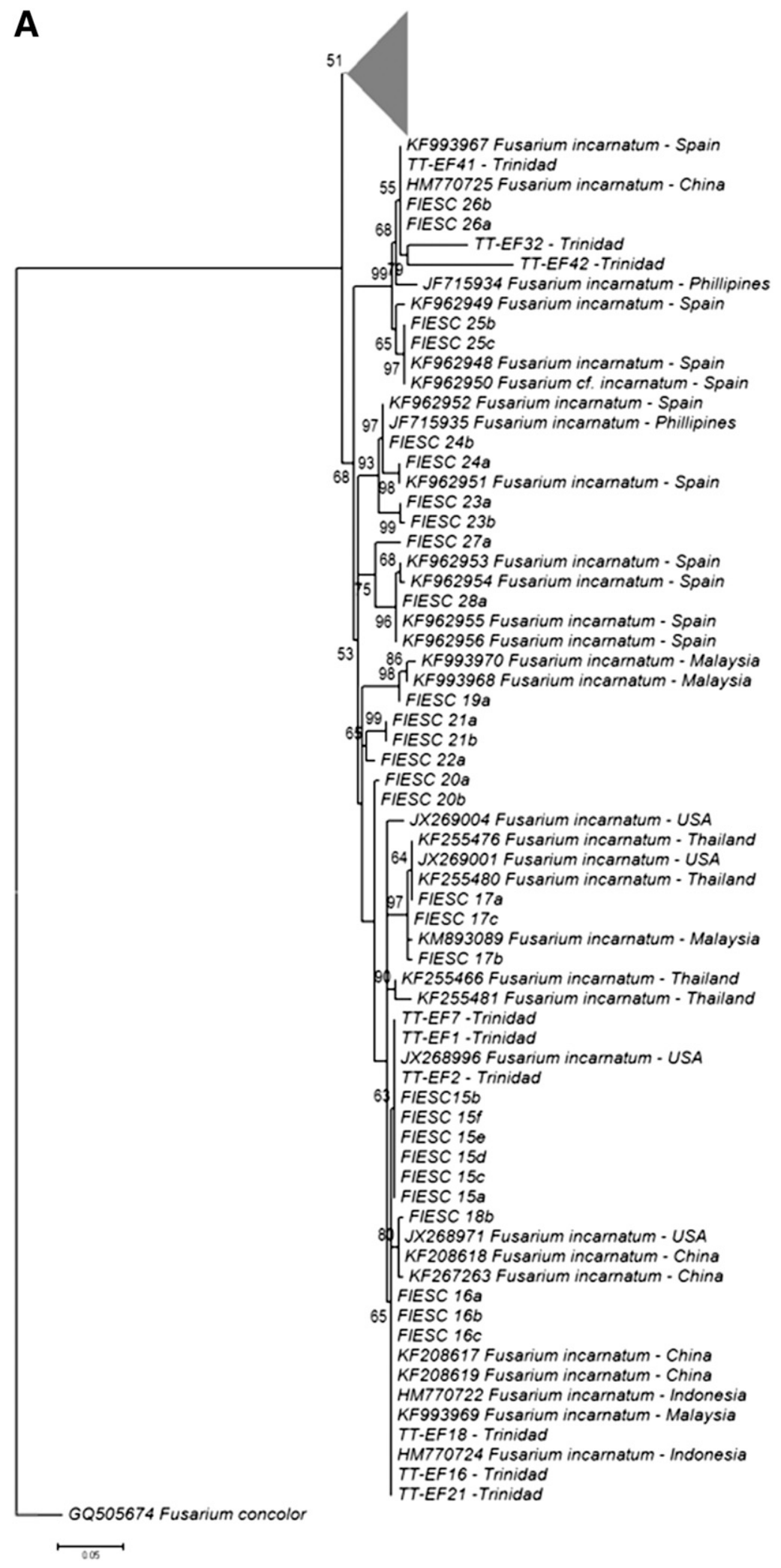

Continued on next page

Fig. 1. Phylogenetic relationships of Fusarium incarnatum-equiseti species complex (FIESC) isolates based on translation elongation factor (EF-1a) gene sequences. The rooted maximum-likelihood (ML) tree (drawn to scale with branch lengths measured in the number of substitutions per site) with the highest log likelihood (-2375.7202) is shown; bootstrap support was calculated from 1,000 replicates and values $>50 \%$ are indicated above the branches. A, The ML tree is collapsed for the $F$. equiseti cluster and $\mathbf{B}$, the ML tree is collapsed for the $F$. incarnatum cluster. 
(Fig. 2A). MP analysis was selected rather than ML (which was used to infer the phylogenetic trees) because the TCS haplotype network was generated using parsimony-based statistics and would enable comparisons of groupings with high bootstrap support. High bootstrap scores $(>90 \%)$ supported haplotype placement which corresponded to distinct groupings of $F$. incarnatum and $F$. equiset $i$ sequences. The patterns of haplotype network corresponded to the
MP topological tree even though the tree was bifurcating and the network appeared to be reticulate at the interior and star-like at the tips. There was no one discernible central haplotype from which most other haplotypes diverged (Fig. 2B). Several haplotypes (many of which were from Spain) were unique and were represented by only one sequence (Table 4). Sequences from Spain were represented in 12 haplotypes, nearly half the total number of

B

JF496577 Fusarium equiseti - Spain KF962942 Fusarium equiseti - Spain JF496571 Fusarium equiseti - Spain FIESC $5 f$

JF496570 Fusarium equiseti - Spain JF496568 Fusarium equiseti - Spain KF962941 Fusarium equiseti - Spain JF496573 Fusarium equiseti - Spain 14 JF496569 Fusarium equiseti -Spain FIESC $5 a 1$ FIESC 5a2

FIESC $5 b 1$ FIESC $5 b 2$

8 KF962940 Fusarium equiseti - Spain - JF496572 Fusarium equiset - Spain FIESC $5 c$

JF496576 Fusarium equiseti - Spain KF962943 Fusarium equiset - Spain JF496575 Fusarium equiseti - Spain KF962944 Fusarium equiseti - Spain FIESC 5d

82 GQ505663 Fusarium equiseti - USA JF496574 Fusarium equiseti - Spain 11 KF962945 Fusarium equiseti - Spain

3. AJ543559 Fusarium equiseti - Denmark

Af. AJ543560 Fusarium equiseti - Norway

99 AJ543558 Fusarium equiseti - Denmark

FIESC 14a

GQ505594 Fusarium equiseti - USA

70 GQ505599 Fusarium equiseti - USA GQ505644 Fusarium equiseti - USA GQ505653 Fusarium equiseti - USA AJ543563 Fusarium equiseti - Denmark

69 AJ543561 Fusarium equiseti - Denmark AJ543562 Fusarium equiseti - Denmark AJ543563 Fusarium equiseti - Denmark AJ543564 Fusarium equiseti - Norway AJ543565 Fusarium equiset - Norway AJ543566 Fusarium equiseti - Norway AJ543557 Fusarium equiseti - Sweden

921 FIESC 6a2

92 FIESC 66

61 FIESC $6 a 1$

FIESC 6a1

FIESC $8 a$

FIESC $8 b$

92. FIESC $12 b$

77 FIESC $12 \mathrm{c}$

FIESC 12a AJ543571 Fusarium equiseti - Malta

FIESC 11a

- FIESC 13

9. FIESC 9c

GQ505601 Fusarium equiseti - USA

51 FIESC $9 b$

FIESC 9a1

FIESC 9 a2

99 GQ505605 Fusarium equiseti - USA

99 GQ505654 Fusarium equiseti - USA

98 FIESC 4 a

FIESC $4 b$

14 FIESC 3a 1

75 FIESC $3 a_{2}$

75 FIESC $3 b$

FIT-EF8 - Trinidad

FIESC 1b

FIESC 1a

FIESC $2 a$

FIESC $2 b$

FIESC 10a1

100 FIESC 10a2

KF962946 Fusarium equiseti - Spain

g9 $\begin{aligned} & \text { KF962946 Fusarium equiset - Spain } \\ & \text { KF962947 Fusarium equiset - Spain }\end{aligned}$

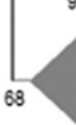

GQ505674 Fusarium concolor

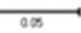

Fig. 1. Continued from previous page. 
haplotypes detected in this aspect of this study. There was some evidence of geographic structure in the distribution of haplotypes. Twelve haplotypes were shared and two of these were represented by country-specific sequences (Spain and the United States). Spain had the highest number of unique and shared haplotypes compared with the other geographical locations. The most diverse haplotype was Hap_16, which was represented by sequences from China, Indonesia, Malaysia, and Trinidad and which consisted exclusively of $F$. incarnatum isolates. Sequences of isolates from Northern Europe (Denmark, Norway, and Sweden) belonged exclusively to two haplotypes (Hap_13 and Hap_14), which consisted of only F. equiseti isolates. Hap_13 was also the most frequent haplotype, with 12 representative sequences. Interestingly, Trinidad and China sequences shared the same two haplotypes (Hap_16 and Hap_33), which consisted of $F$. incarnatum isolates. Trinidad sequences also shared one haplotype with the United States (Hap_21), which also consisted of $F$. incarnatum isolates.

When the distribution of haplotypes was plotted on to a world map (Fig. 2C), there was some correlation between haplotype diversity and geographical imprint. Spain had the highest haplotype diversity, perhaps because both $F$. equiseti and $F$. incarnatum sequences were represented; followed by the United States, which contributed both $F$. equiseti and $F$. incarnatum sequences to the data set; then by countries representing Southeast Asia (China, Indonesia, Malaysia, Thailand, and Philippines) and Trinidad (both regions were represented by only $F$. incarnatum sequences).

\section{DISCUSSION}

The objectives of this study were to (i) determine the identity of Fusarium spp. infecting bell pepper in Trinidad, (ii) compare the level of DNA polymorphism of ITS and EF-1a sequences, (iii) determine the haplotype diversity and distribution, and (iv) infer the phylogenetic relationships of FIESC isolates. Separate sequence data sets were prepared and analyzed for FIESC type strains representing 30 phylogenetic species obtained from the FUSARIUMID database, and for 79 FIESC isolates from 11 different countries.

The EF-1a sequences outperformed the ITS sequences in providing superior taxa resolution for members of the FIESC. It is known that for some fungal groups of Ascomycetes (e.g., Trichoderma and Fusarium), EF-1a sequences are recommended for species delineation (O'Donnell et al. 2015). When the distance to the nearest neighbor for fungal species, especially for Ascomycetes (e.g., Penicillium and Fusarium), are examined for ITS sequences, very low genetic distance values are obtained and, hence, poor resolution and taxon placement in phylogenetic inference (Vitale et al. 2011). For Fusarium spp., ITS sequences are also unable to resolve recent lineages (O'Donnell et al. 2013). In general, slowly evolving genes (e.g., EF-1a and RPB2) are more suitable for inferring deep phylogenies, while gene sequences undergoing faster evolutionary rates (e.g., TUB2) perhaps capture more recent evolutionary and speciation events. Sections of protein-coding genes (e.g., EF-1a gene) theoretically satisfy both requirements because these sequences consist of variable intronic sequences and conserved exonic sequences (Stielow et al. 2015). According to the results of this study and others, it is important to determine the level of DNA polymorphism in sequences to be used for intraspecies identification and for phylogenetic inference because this information has a direct impact on confidence of identity and resolution of phylogenetic placement and phylogenetic signal, and affects genetic diversity indices, including haplotype diversity and distribution (O'Donnell et al. 2015).

The low level of genetic diversity found for FIESC isolates infecting bell pepper in Trinidad based on EF-1a sequences is apparently not uncommon because Castellá and Cabañes (2014) also reported a low level of phylogenetic species diversity for isolates associated with symptomless infection of wheat in Spain. However, the results of this study indicate that Spain is host to the largest number of EF-1a haplotypes and the most diverse EF-1a haplotypes infecting a wide range of plant species.

Based on ML analysis, there was evidence of clustering based on geography as $F$. equiseti isolates from Spain which formed a separate, well-supported cluster. Similarly, isolates from Northern Europe (i.e., Denmark and Norway) and the United States were grouped into a separate cluster with moderate support. These two distinct groupings were also reported by Marín et al. (2012) as type II $F$. equiseti for Spain isolates and type I $F$. equiseti for the Northern Europe isolates.

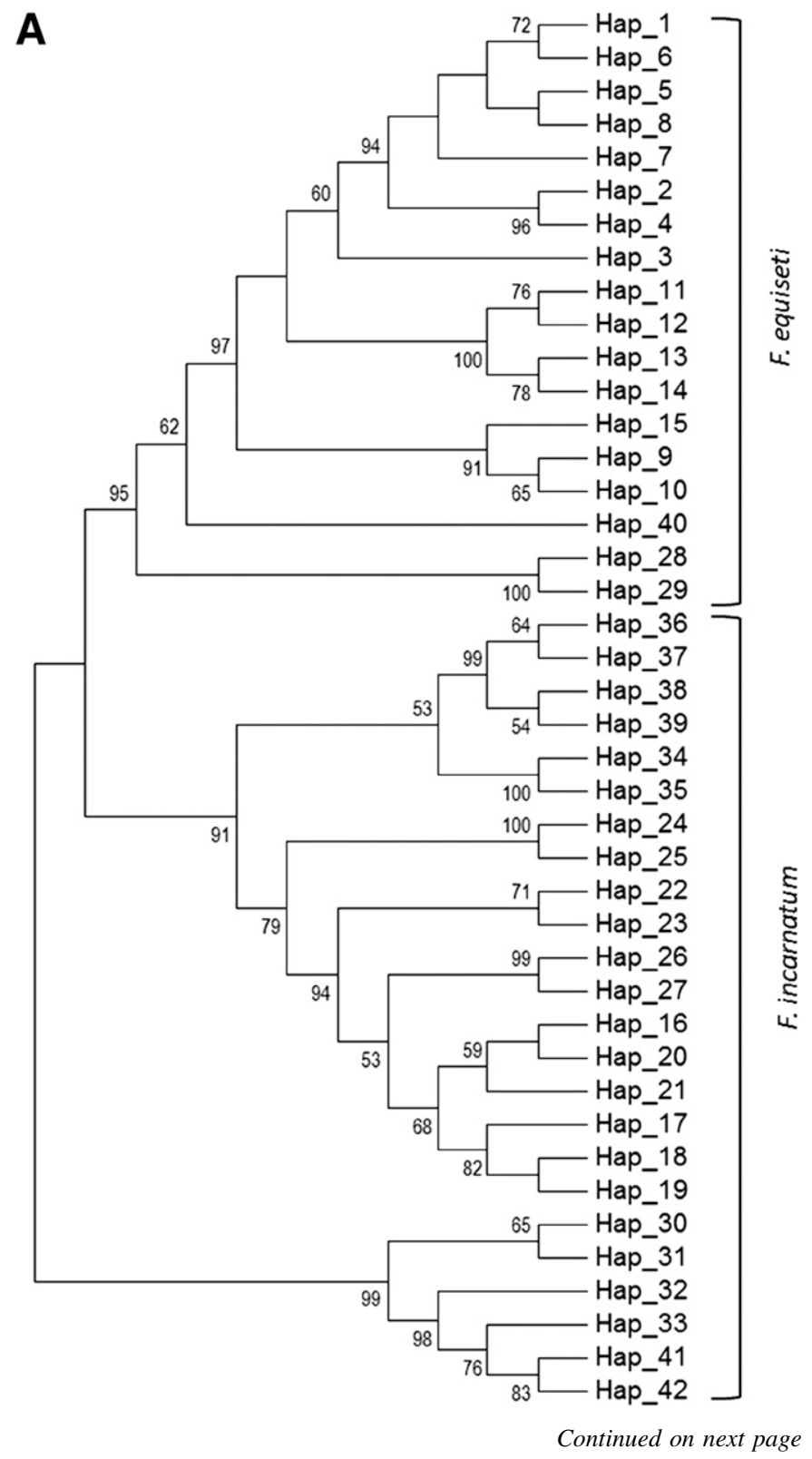

Fig. 2. A, Maximum-parsimony (MP) analysis of haplotypes. The consistency index is 0.764 , the retention index is 0.932 , and the composite index is 0.772 for all sites. The percentage of replicate trees in which the associated taxa clustered together in the bootstrap test $(1,000$ replicates) is shown next to the branches. All positions containing gaps and missing data were eliminated. There were 154 positions in the final dataset. The tree presented is unrooted. $\mathbf{B}$, TCS haplotype network generated for global translation elongation factor (EF-1a) sequences representing 11 countries. The size of the circle indicates the relative frequency of sequences belonging to a particular haplotype ( smallest circle $=1$ sequence to largest circle $=13$ sequences). Hatch marks along the network branches indicate the number of mutations. Each color represents a different geographic location. C. Distribution of haplotypes and haplotype diversity according to geographic location. Each color represents a different geographic location. 
The majority of $F$. incarnatum sequences in the data set were from isolates collected in warm temperate and tropical regions or climates. This finding is in keeping with the global distribution of $F$. incarnatum according to the United States Department of Agriculture-Agricultural Research Service (USDA-ARS) fungal database (https://nt.ars-grin.gov/fungaldatabases/). Conversely, the distribution of $F$. equiseti is described as cosmopolitan on the same fungal database. Geography and climate are reported to be two important epidemic-associated factors that influence the occurrence and establishment of Fusarium spp. as plant pathogens (Castellá and Cabañes 2014). Interestingly, isolates associated with human infections in Thailand were positioned with other sequences of plant-infecting isolates which may indicate little host specificity among members of the species complex. The USDA-ARS fungal database has a record of $269 \mathrm{~F}$. incarnatum-host combinations and $280 \mathrm{~F}$. equiseti-host combinations (including synonyms of both fungal species). Fusarium spp. demonstrate a high level of diversity in their morphological, physiological, and cultural characteristics
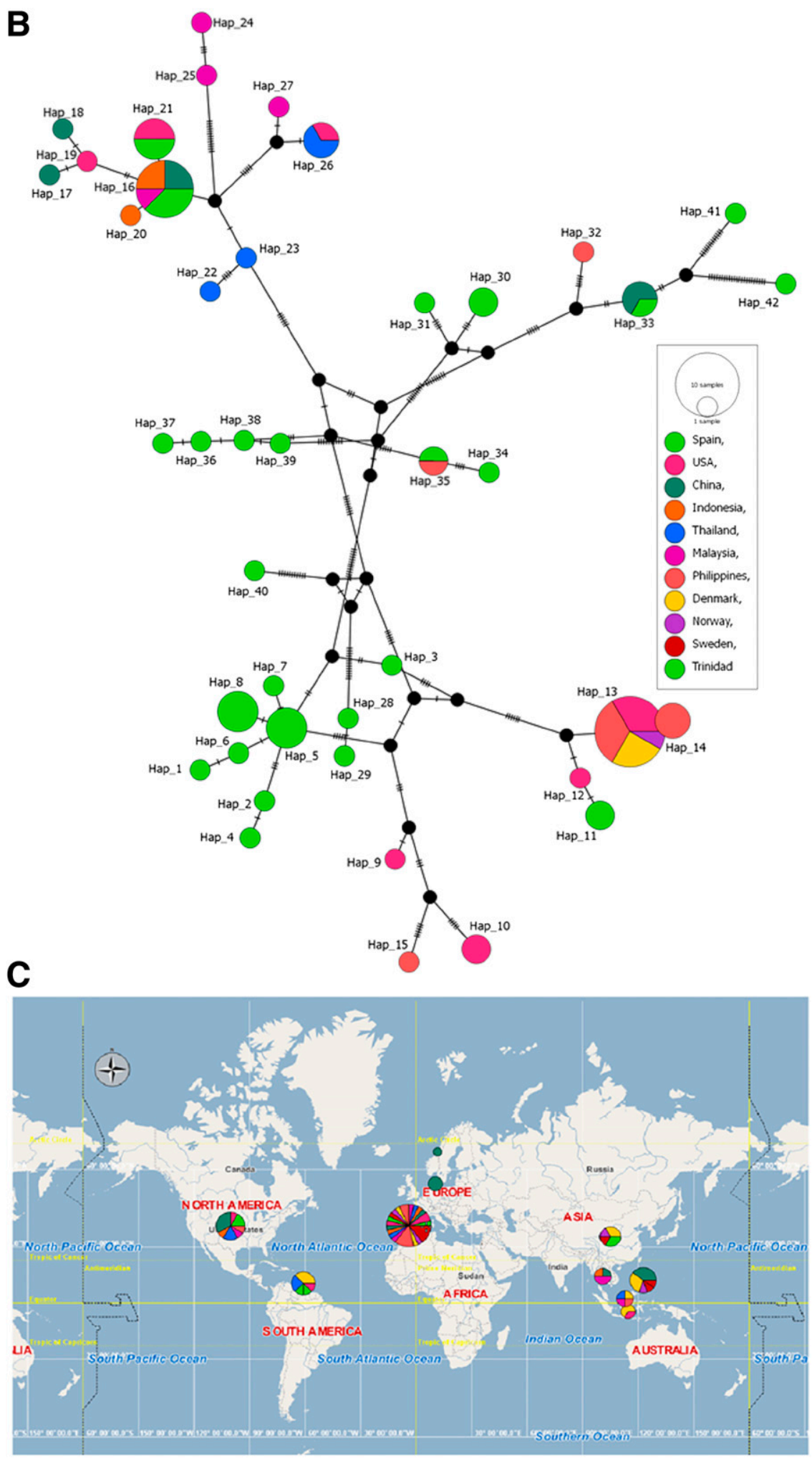

Fig. 2. Continued from previous page. 
(Booth 1971; Leslie and Summerell 2006). This variation may reflect the ability of different Fusarium spp. to survive in a wide range of ecological niches as pathogens, endophytes, and soil saprophytes in temperate and tropical climates (Nelson et al. 1983).

Many of the haplotypes were produced as a result of InDels, which are informative when working with highly similar sequences, especially those of a species complex such as FIESC. However, suitable algorithms are still to be developed that take such InDels into account and allow for meaningful biological interpretation (Salzburger et al. 2011). In naturally occurring field populations,

TABLE 4. Haplotype frequency (Freq) and distribution for global isolates based on translation elongation factor gene sequences

\begin{tabular}{|c|c|c|}
\hline Haplotype $^{\mathrm{a}}$ & Freq & Sequences \\
\hline Hap_1 & 1 & JF496568, Spain \\
\hline Hap_2 & 1 & JF496573, Spain \\
\hline Hap_3 & 1 & JF496572, Spain \\
\hline Hap_4 & 1 & JF496569, Spain \\
\hline Hap_5 & 4 & $\begin{array}{l}\text { JF496571, Spain; JF496577, Spain; KF962942, } \\
\text { Spain; JF496570, Spain }\end{array}$ \\
\hline Hap_6 & 1 & KF962941, Spain \\
\hline Hap_7 & 1 & KF962940, Spain \\
\hline Hap_8 & 4 & $\begin{array}{l}\text { JF496576, Spain; KF962943, Spain; JF496575, } \\
\text { Spain; KF962944, Spain }\end{array}$ \\
\hline Hap_9 & 1 & GQ505601, United States \\
\hline Hap_10 & 2 & $\begin{array}{l}\text { GQ505605, United States; GQ505654, } \\
\text { United States }\end{array}$ \\
\hline Hap_11 & 2 & JF496574, Spain; KF962945, Spain \\
\hline Hap_12 & 1 & GQ505663, United States \\
\hline Hap_13 & 1 & $\begin{array}{l}\text { GQ505594, United States; GQ505599, } \\
\text { United States; GQ505644, United States; } \\
\text { GQ505653, United States; AJ543563, } \\
\text { Denmark; AJ543561, Denmark; AJ543562, } \\
\text { Denmark; AJ543563, Denmark; AJ543564, } \\
\text { Denmark; AJ543565, Norway; AJ543566, } \\
\text { Norway; AJ543557, Sweden }\end{array}$ \\
\hline Hap_14 & 3 & $\begin{array}{l}\text { AJ543558, Denmark; AJ543559, Denmark; } \\
\text { AJ543560, Norway }\end{array}$ \\
\hline Hap_15 & 1 & AJ543571, Malta \\
\hline Hap_16 & 8 & $\begin{array}{l}\text { KF208617, China; KF208619, China; } \\
\text { HM770722, Indonesia; KF993969, Malaysia; } \\
\text { HM770724, Indonesia; TTEF16, Trinidad; } \\
\text { TTEF18, Trinidad; TTEF21, Trinidad }\end{array}$ \\
\hline Hap_17 & 1 & KF208618, China \\
\hline Hap_18 & 1 & KF267263, China \\
\hline Hap_19 & 1 & JX268971, United States \\
\hline Hap_20 & 1 & HM770723, China \\
\hline Hap_21 & 4 & $\begin{array}{l}\text { GQ915510, United States; JX268996, } \\
\text { United States; TTEF1, Trinidad; TTEF7, Trinidad }\end{array}$ \\
\hline Hap_22 & 1 & KF255481, Thailand \\
\hline Hap_23 & 1 & KF255466, Thailand \\
\hline Hap_24 & 1 & KF993970, Malaysia \\
\hline Hap_25 & 1 & KF993968, Malaysia \\
\hline Hap_26 & 3 & $\begin{array}{l}\text { KF255480, Thailand; KF255476, Thailand; } \\
\text { JX269001, United States }\end{array}$ \\
\hline Hap_27 & 1 & KM893089, Malaysia \\
\hline Hap_28 & 1 & KF962946, Spain \\
\hline Hap_29 & 1 & KF962947, Spain \\
\hline Hap_30 & 2 & KF962948, Spain; KF962950, Spain \\
\hline Hap_31 & 1 & KF962949, Spain \\
\hline Hap_32 & 1 & JF715934, Philippines \\
\hline Hap_33 & 3 & $\begin{array}{l}\text { HM770725, China; KF993967, China; TTEF41, } \\
\text { Trinidad }\end{array}$ \\
\hline Hap_34 & 1 & KF962951, Spain \\
\hline Hap_35 & 2 & KF962952, Spain; JF715935, Philippines \\
\hline Hap_36 & 1 & KF962953, Spain \\
\hline Hap_37 & 1 & KF962954, Spain \\
\hline Hap_38 & 1 & KF962955, Spain \\
\hline Hap_39 & 1 & KF962956, Spain \\
\hline Hap_40 & 1 & KF962957, Spain \\
\hline Hap_41 & 1 & TTEF32, Trinidad \\
\hline Hap_42 & 1 & TTEF42, Trinidad \\
\hline
\end{tabular}

a Haplotype: underscore was used in the haplotype designations to differentiate them from the haplotypes obtained for the Fusarium incarnatum-equiseti species complex subclade species analysis. there will be a mixture of ancestral haplotypes and surviving descendants; however, the relationship between the two may be reticulate and not bifurcate, due to nondichotomous historical events (e.g., recombination, incomplete lineage sorting, horizontal gene transfer, and deep coalescence) (Posada and Crandall 2001). These events would leave different "signatures" in the data and result in different patterns in a given network. In fact, Ma et al. (2013) suggested that horizontal gene transfer played a critical role in the evolution of Fusarium genomes. The coalescent theory proposes that high-frequency haplotypes may have been present in the population for a long time and, therefore, the less-frequent haplotypes may represent more recent mutation events. This is supported by the findings of this study, where several of the terminal haplotypes located at the tips in the network were produced from a single mutation event indicated by a single hatch mark along the branch. These network tips were also unique haplotypes represented by one sequence and it is likely that sufficient time had not elapsed to accumulate mutations that are host or geographic associated to an extent where the sequence contributed significantly to nucleotide divergence (Carbone and Kohn 2004). The terminal haplotypes located at the network tips as well as unique haplotypes may represent more recent lineages rather than older ones. The older haplotypes would be positioned toward the interior of the network. Newer haplotypes would also have a more restricted geographical association and the older haplotypes have a broader geographical distribution if there is suspected restricted gene flow (Carbone and Kohn 2004). However, in a reticulate network, there can be both older and newer haplotypes positioned at the internal nodes of the network. There is no straightforward interpretation of this type of network, with resulting difficulty in understanding its biological relevance (e.g., the pattern may represent real evolutionary events but it is not clear which ones may, in fact, be a mathematical anomaly) (Morrison 2005). As such, these haplotype networks are considered to be an exploratory tool to understanding the phylogenetic hypothesis that describes the relationships among closely related species such as those of the FIESC.

Conservative exploration of the haplotype network and the haplotype distribution on the world map illustrate that the F. equiseti strains were separated from the $F$. incarnatum strains by a number of mutational steps with separation of isolates according to geographical location (e.g., Spain, the United States, Denmark, and Norway). It is proposed that both direct and indirect influences on the dissemination of the pathogen may explain the haplotype network, where there may have been recent anthropogenic movement of the pathogen in contaminated plant material and dispersal of inoculum that originated from other hosts, followed by rapid host adaptation with a potential for wide spatial distribution. In addition, hundreds of millions of tons of Saharan dust is carried off the coast of Africa and other areas in interior Africa to the Caribbean and South America each year, usually during the hurricane season. The dust is seen as a continuous Saharan Air Layer (NASA Earth Observatory, http://earthobservatory.nasa.gov/IOTD/view.php?id=81864\&src= eoa-iotd) which provides a medium for movement of over 300 microbes that are pathogenic to plants, animals, and humans, the

TABLE 5. Analysis of insertion/deletion mutation (InDel) data for haplotype sequences

\begin{tabular}{lc}
\hline InDel index & Data \\
\hline Total number of InDel sites analyzed & 30 \\
Total number of (InDel and non-InDel) sites & $348+30=378$ \\
$\quad$ analyzed & 21 \\
Total number of InDels events analyzed, $I$ & 1.81 \\
Average InDel length event & 1.65 \\
Average InDel length & 27 \\
Number of InDel Haplotypes & 0.928 \\
InDel Haplotype Diversity & 3.094 \\
InDel Diversity, $k(i)$ & 0.008 \\
InDel Diversity per site, $\pi$ & \\
\hline
\end{tabular}


majority of which are plant-pathogenic fungi and include Fusarium spp. (Garrison et al. 2006) (A. Ramsubhag. personal communication). Fusarium spp. are well adapted to long-distance atmospheric transport because their asexual spores are resistant to desiccation, ultraviolet radiation, and other harsh environmental conditions.

There have been reports of other Fusarium spp. infecting bell pepper in Belgium, Canada, the Netherlands, and the United Kingdom; for example, F. oxysporum, F. proliferatum, F. solani, and F. lactis species complexes have been shown to produce mycotoxins in bell pepper fruit (Van Poucke et al. 2012; Yang et al. 2011). However, this is the first report of FIESC infecting bell pepper fruit. Because members of the FIESC are known mycotoxin producers, the level of exposure after consumption of infected bell pepper fruit must be determined. Van Poucke et al. (2012) purported that, for $F$. lactis infecting bell pepper fruit in Belgium, the affected part of the fruit may be removed and consumed because there was negligible movement of mycotoxins into healthy flesh and, therefore, a low level of mycotoxins and risk of exposure. Future research will have to include (i) a more detailed assessment involving sequence analysis of multiple genes and development of microsatellites, (ii) screening FIESC (Trinidad) isolates for the production of mycotoxins in bell pepper, and (iii) genetic chemotyping of isolates based on toxin biosynthesis gene sequence analysis.

\section{ACKNOWLEDGMENTS}

This work was funded, in part, by The University of the West Indies Campus Research and Publications Fund, grant number CRP.3.NOV11.8.

\section{LITERATURE CITED}

Antonissen, G., Martel, A., Pasmans, F., Ducatelle, R., Verbrugghe, E., Vandenbroucke, V., Haesebrouck, F., Van-Immerseel, F., and Croubels, S. 2014. The impact of Fusarium mycotoxins on human and animal host susceptibility to infectious diseases. Nat. Cent. Biotechnol. Inf. 6:430-452.

Aoki, T., O'Donnell, K., and Geiser, D. 2014. Systematics of key phytopathogenic Fusarium species: Current status and future challenges. J. Gen. Plant Pathol. 80:189-201.

Arif, M., Chawla, S., Zaidi, M. W., Rayar, J. K., Variar, M., and Singh, U. S. 2014. Development of specific primers for genus Fusarium and F. solani using rDNA sub-unit and transcription elongation factor (TEF-1 $\alpha$ ) gene. Afr. J. Biotechnol. 11:444-447.

Bai, G. H., Desjardins, A. E., and Plattner, R. D. 2002. Deoxynivalenolnonproducing Fusarium graminearum causes initial infection; but does not cause disease spread in wheat spikes. Mycopathologia 153:91-98.

Benyon, F. L., Burgess, L. W., and Sharp, P. J. 2000. Molecular genetic investigations and reclassification of Fusarium species in sections Fusarium and Roseum. Mycol. Res. 104:1164-1174.

Booth, C. 1971. The Genus Fusarium. Commonwealth Mycological Institute, Surrey, UK.

Carbone, I., and Kohn, L. 2004. Inferring process from pattern in fungal population genetics. In: Applied Mycology and Biotechnology, Vol. 4, Fungal Genomics. Elsevier Science B.V., Amsterdam.

Castellá, G., and Cabañes, F. J. 2014. Phylogenetic diversity of Fusarium incarnatum-equiseti Species complex isolated from Spanish wheat. Antonie Leeuwenhoek 106:309-317.

Clement, M., Snell, Q., Walke, P., Posada, D., and Crandall, K. 2002. TCS: Estimating gene genealogies. Proc. 16th Int. Parallel Distrib. Process Symp. 2:184.

Cummings, M. P., Neel, M. C., and Shaw, K. 2008. A genealogical approach to quantifying lineage divergence. Evolution 62:2411-2422.

Dean, R., Van-Kan, A. L., Pretorius, Z. A., Hammond-Kosack, K. E., Di Pietro, A., Spanu, D., Rudd, J. J., Dickman, M., Kahmann, R., Ellis, J., and Foster, G. D. 2012. The top 10 fungal pathogens in molecular plant pathology. Mol. Plant Pathol. 13:414-430.

Desjardins, A. E., Proctor, R. H., Bai, G., McCormick, S. P., Shaner, G., Buechley, G., and Hohn, T. M. 1996. Reduced virulence of trichothecenenonproducing mutants of Gibberella zeae in wheat field tests. Mol. PlantMicrobe Interact. 9:775-781.

Desmond, O. J., Manners, J. M., Stephens, A. E., Maclean, D. J., Schenk, P. M., Gardiner, D. M., Munn, A. L., and Kazan, K. 2008. The Fusarium mycotoxin deoxynivalenol elicits hydrogen peroxide production, programmed cell death and defence responses in wheat. Mol. Plant Pathol. 9:435-445.
Dubey, S. C., Priyanka, K., and Singh, V. 2014. Phylogenetic relationship between different race representative populations of Fusarium oxysporum f. sp. ciceris in respect of translation elongation factor- $1 \alpha, \beta$-tubulin, and internal transcribed spacer region genes. Arch. Microbiol. 196:445-452.

Etherington, G. J., Dicks, J., and Roberts, J. N. 2005. Recombination analysis tool (RAT): A program for the high-throughput detection of recombination. Bioinformatics 21:278-281.

Excoffier, L. G., Laval, S., and Schneider, S. 2005. Arlequin ver. 3.0: An integrated software package for population genetics data analysis. Evol. Bioinf. Online 1:47-50.

Fu, X.-Y. 1997. Statistical tests of neutrality of mutations against population growth, hitchhiking and background selection. Genetics 147:915-925.

Fu, X.-Y., and Li, W.-H. 1993. Statistical tests of neutrality of mutations. Genetics 133:693-709.

Garrison, V. H., Forem, W. T., Genualdi, S., Griffin, D. W., Kellogg, C. A., Majewski, M. S., Mohammed, A., Ramsubhag, A., Shinn, E. A., Simonich, S. L., and Smith, G. W. 2006. Saharan dust-A carrier of persistent organic pollutants, metals and microbes to the Caribbean? Rev. Biol. Trop. 54:9-21.

Geiser, D. M., Jiménez-Gasco, M. M., Kang, S., Makalowska, I., Veeraraghavan, N., Ward, T. J., Zhang, N., Kuldau, G. A., and O'Donnell, K. 2004. FUSARIUM-ID v. 1.0: A DNA sequence database for identifying Fusarium. Eur. J. Plant Pathol. 110:473-479.

Ilgen, P., Maier, F., and Schafer, W. 2008. Trichothecenes and lipases are hostinduced and secreted virulence factors of Fusarium graminearum. Cereal Res. Commun. 36:421-428.

Leigh, J. W., and Bryant, D. 2015. POPART: Full-feature software for haplotype network construction. Methods Ecol. Evol. 6:1110-1116.

Leslie, J. F., and Summerell, B. A. 2006. The Fusarium Laboratory Manual. Blackwell Publishing, Ames, IA.

Librado, P., and Rozas, J. 2009. DNASP v5: A software for comprehensive analysis of DNA polymorphism data. Bioinf. Appl. Note 25:1451-1452.

Ma, L., Geiser, D. M., Proctor, R. H., Rooney, A. P., O’Donnell, K., Trail, F., Gardiner, D. M., Manners, J. M., and Kazan, K. 2013. Fusarium pathogenomics. Annu. Rev. Microbiol. 67:399-416.

Marín, P., Moretti, A., Ritieni, A., Jurado, M., Vázquez, C., and González-Jaén, M. T. 2012. Phylogenetic analyses and toxigenic profiles of Fusarium equiseti and Fusarium acuminatum isolated from cereals from Southern Europe. Food Microbiol. 31:229-237.

Mohammed, A. 2013. Market Profile for Sweet Pepper in Trinidad \& Tobago. The Common Fund for Commodities/European Union (CFC/EU)-financed project: "Increased Production of Vegetables and Herbs through the use of Protected Agriculture (PA) in the Caribbean" being implemented by CARDI in Haiti, Jamaica and, Trinidad \& Tobago. Online publication. http://www.cardi.org/cfc-pa/files/downloads/2013/11/Publ-22-MarketProfile-Sweet-pepper-TT-Aziz-M.pdf

Moretti, A. 2009. Taxonomy of Fusarium genus, a continuous fight between lumpers and splitters. Inst. Sci. Food Prod. 117:7-13.

Morrison, D. A. 2005. Networks in phylogenetic analysis: New tools for population biology. Int. J. Parasitol. 35:567-82.

Nelson, P. E., Toussoun, T. A., and Marasas, W. O., eds. 1983. Fusarium Species: An Illustrated Manual for Identification. Pennsylvania State University Press, PA.

O’Donnell, K., Kistler, H. C., Tacke, B. K., and Casper, H. H. 2000. Gene genealogies reveal global phylogeographic structure and reproductive isolation among lineages of Fusarium graminearum, the fungus causing wheat scab. Proc. Natl. Acad. Sci. USA 97:7905-7910.

O’Donnell, K., Rooney, A. P., Proctor, R. H., Brown, D. W., McCormick, S. P., Ward, T. J., Frandsen, R. J., Lysøe, E., Rehner, S. A., Aoki, T., Robert, V. A., Crous, P. W., Groenewald, J. Z., Kang, S., and Geiser, D. M. 2013. Phylogenetic analyses of RPB1 and RPB2 support a middle Cretaceous origin for a clade comprising all agriculturally and medically important fusaria. Fungal Genet. Biol. 52:20-31.

O’Donnell, K., Sutton, D. A., Rinaldi, M. G., Sarver, B. A., Balajee, S. A., Schroers, H. J., Summerbell, R. C., Robert, V. A., Crous, P. W., Zhang, N., Aoki, T., Jung, K., Park, J., Lee, Y. H., Kang, S., Park, B., and Geiser, D. M. 2010. Internet-accessible DNA sequence database for identifying Fusaria from human and animal infections. J. Clin. Microbiol. 48:3708-3718.

O’Donnell, K., Ward, T. J., Geiser, D. M., Corby, K. H., and Aoki, T. 2004. Genealogical concordance between the mating type locus and seven other nuclear genes supports formal recognition of nine phylogenetically distinct species within the Fusarium graminearum clade. Fungal Genet. Biol. 41: 600-623.

O’Donnell, K., Ward, T. J., Robert, V. A. R. G., Crous, P. W., Geiser, D. M., and Kang, S. 2015. DNA-sequence based identification of Fusarium: Current status and future directions. Phytoparasitica 43:583-595.

Peay, K., Kennedy, P., and Bruns, T. 2008. Fungal community ecology: A hybrid beast with a molecular master. Bioscience 58:799-810.

Ploetz, R. C. 2006. Fusarium-induced diseases of tropical, perennial crops. Phytopathology 96:648-652. 
Posada, D., and Crandall, K. A. 2001. Evaluation of methods for detecting recombination from DNA sequences: Computer simulations. Proc. Natl. Acad. Sci. 98:13757-13762.

Proctor, R. H., Hohn, T. M., and McCormick, S. P. 1995. Reduced virulence of Gibberella zeae caused by disruption of a trichothecene toxin biosynthetic gene. Mol. Plant-Microbe Interact. 8:593-601.

Ramdial, H., Hosein, F., and Rampersad, S. N. 2016. First report of Fusarium incarnatum associated with fruit disease of bell peppers in Trinidad. Plant Dis. 100:526.

Ramdial, H., and Rampersad, S. N. 2014. Characterization of Colletotrichum spp. causing anthracnose of bell pepper (Capsicum annuum L.) in Trinidad. Phytoparasitica 43:37-49.

Rozas, J., Sanchez-Del Barrio, J. C., Messeguer, X., and Rozas, R. 2003. DNASP, DNA polymorphism analyses by the coalescent and other methods. Bioinformatics 19:2496-2497.

Salzburger, W., Ewing, G. B., and Von Haeseler, A. 2011. The performance of phylogenetic algorithms in estimating haplotype genealogies with migration. Mol. Ecol. 20:1952-1963.

Skovgaard, K., Rosendahl, S., O’Donnell, K., and Nirenberg, H. I. 2003. Fusarium commune is a new species identified by morphological and molecular phylogenetic data. Mycologia 95:630-636.

Soren, K. R., Gangwar, P., Chaudhary, R. G., and Datta, S. 2015. Population distribution and genetic relatedness in Indian Fusarium udum isolates based on ribosomal internal transcribe spacer and elongation factor. J. Environ. Biol. 36:1063-1070.

Stielow, J. B., Lévesque, C. A., Seifert, K. A., Meyer, W., Irinyi, L., Smits, D., Renfurm, R., Verkley, G. J. M., Groenewald, M., Chaduli, D., Lomascolo, A., Welti, S., Lesage-Meessen, L., Favel, A., Al-Hatmi, A. M. S., Damm, U., Yilmaz, N., Houbraken, J., Lombard, L., Quaedvlieg, W., Binder, M., Vaas, L. A. I., Vu, D., Yurkov, A., Begerow, D., Roehl, O., Guerreiro, M., Fonseca, A., Samerpitak, K., van Diepeningen, A. D., Dolatabadi, S., Moreno, L. F., Casaregola, S., Mallet, S., Jacques, N., Roscini, L., Egidi, E., Bizet, C., Garcia-Hermoso, D., Martín, M. P., Deng, S., Groenewald, J. Z., Boekhout, T., de Beer, Z. W., Barnes, I., Duong, T. A., Wingfield, M. J., de Hoog, G. S., Crous, P. W., Lewis, C. T., Hambleton, S., Moussa, T. A. A., Al-Zahrani, H. S., Almaghrabi, O. A., Louis-Seize, G., Assabgui, R., McCormick, W., Omer, G., Dukik, K., Cardinali, G., Eberhardt, U., de Vries, M., and Robert, V. 2015. One fungus, which genes? Development and assessment of universal primers for potential secondary fungal DNA barcodes. Persoonia 35:242-263.

Tajima, F. 1989. Statistical method for testing the neutral mutation hypothesis by DNA polymorphism. Genetics 123:585-595.
Tamura, K., Stecher, G., Peterson, D., Filipski, A., and Kumar, S. 2013. MEGA6: Molecular Evolutionary Genetics Analysis version 6.0. Mol. Biol. Evol. 30:2725-2729.

Taylor, J., Jacobson, D., Kroken, S., Kasuga, T., Geiser, D., Hibbett, D., and Fisher, M. 2000. Phylogenetic species recognition and species concept in fungi. Fungal Genet. Biol. 31:21-32.

Templeton, A. R., Crandall, K. A., and Sing, C. F. 1992. A cladistics analysis of phenotypic associations with haplotypes inferred from restriction endonuclease mapping and DNA sequence data III. Cladogram estimation. Genetics 132:619-633.

Thrane, U. 2001. Developments in the taxonomy of Fusarium species based on secondary metabolites. Pages 29-49 in: Fusarium: Paul E. Nelson Memorial Symposium. B. A. Summerell, J. F. Leslie, D. Backhouse, W. L. Bryden, and L. W. Burgess, eds. American Phytopathological Society Press, St. Paul, MN.

Torp, M., and Nirenberg, H. I. 2004. Fusarium langsethiae sp. nov. on cereals in Europe. Int. J. Food Microbiol. 95:247-256.

van Poucke, K., Monbaliu, S., Munaut, F., Heungens, K., De Saeger, S., and Van Hove, F. 2012. Genetic diversity and mycotoxin production of Fusarium lactis species complex isolates from sweet pepper. Int. J. Food Microbiol. 153:28-37.

Vitale, S., Santori, A., Wajnberg, E., Castagnone-Sereno, P., Luongo, L., and Belisario, A. 2011. Morphological and molecular analysis of Fusarium lateritium, the cause of gray necrosis of hazelnut fruit in Italy. Phytopathology 101:679-686.

Waalwijk, C., deKoning, J. R. A., Baayen, R. P., and Gams, W. 1996. Discordant groupings of Fusarium spp. from sections Elegans, Liseola and Dlaminia based on ribosomal ITS1 and ITS2 sequences. Mycologia 88: 361-368.

White, T. J., Bruns, T., Lee, S., and Taylor, J. W. 1990. PCR Protocols: A Guide to Methods and Applications. Academic Press Inc., New York.

Woloshuk, C. P., and Shim, W.-B. 2013. Aflatoxins, fumonisins, and trichothecenes: A convergence of knowledge. FEMS Microbiol. Rev. 37:94-109.

Yang, Y., Bouras, N., Yang, J., Howard, R. J., and Strelkov, S. E. 2011. Mycotoxin production by isolates of Fusarium lactis from greenhouse sweet pepper (Capsicum annuum). Int. J. Food Microbiol. 151:150-156.

Zarrin, M., Ganj, F., and Faramarzi, S. 2016. Analysis of the rDNA internal transcribed spacer region of the Fusarium species by polymerase chain reaction-restriction fragment length polymorphism. Biomed. Rep. 4:471-474.

Zwickl, D. J. 2006. Genetic algorithm approaches for the phylogenetic analysis of large biological sequence datasets under the maximum likelihood criterion. Ph.D. dissertation, The University of Texas at Austin. 